\title{
A QUANTITATIVE VALIDATED METHOD USING LIQUID CHROMATOGRAPHY AND CHEMOMETRIC ANALYSIS FOR EVALUATION OF RAW MATERIAL OF Maytenus ilicifolia (SCHRAD.) PLANCH., CELASTRACEAE
}

\author{
Flávio Luís Beltrame* \\ Departamento de Ciências Farmacêuticas, Universidade Estadual de Ponta Grossa, Av. General Carlos Cavalcanti, 4748, \\ 84030-900 Ponta Grossa - PR, Brasil
}

Rubiana Mara Mainardes e Najeh Maissar Khalil

Departamento de Farmácia, Universidade Estadual do Centro-Oeste. Rua Simeão Camargo Varela de Sá, 3, 85040-080 Guarapuava - PR, Brasil

Rosilene Aparecida Prestes, Alessandro Nogueira e Ivo Mottin Demiate

Departamento de Engenharia de Alimentos, Universidade Estadual de Ponta Grossa, Av. General Carlos Cavalcanti, 4748, 84030-900 Ponta Grossa - PR, Brasil

Quezia Bezerra Cass

Departamento de Química, Universidade Federal de São Carlos, CP 676, 13560-970 São Carlos - SP, Brasil

Recebido em 28/3/11; aceito em 2/7/11; publicado na web em 19/8/11

\begin{abstract}
The hydroalcoholic extracts prepared from standard leaves of Maytenus ilicifolia and commercial samples of espinheira-santa were evaluated qualitatively (fingerprinting) and quantitatively. In this paper, fingerprinting chromatogram coupled with Principal Component Analysis (PCA) is described for the metabolomic analysis of standard and commercial espinheira-santa samples. The epicatechin standard was used as an external standard for the development and validation of a quantitative method for the analysis in herbal medicines using a photo diode array detector. This method has been applied for quantification of epicatechin in commercialized herbal medicines sold as espinheira-santa in Brazil and in the standard sample of M. ilicifolia.
\end{abstract}

Keywords: Maytenus ilicifolia; chemometric analysis; liquid chromatography.

\section{INTRODUCTION}

Tea is one of the most widely consumed beverages in the world, being used both for nutrition and medicine. Properties associated with the consumption of tea are attributed especially to their chemical compounds, which are as diverse as plants used for this purpose. In recent years, several studies have shown that regular consumption of certain teas may reduce the risk of several types of diseases. ${ }^{1-3}$

As described by Chen et al.,$^{4}$ the chemical composition of tea includes, among other constituents, polyphenols as catechins or flavan-3-ols, theaflavins, thearubigins, and proanthocyanidins; these compounds could be responsible for tea bioactivities including antioxidant, improving immune response, anti-atherosclerosis, antihypertension, anti-infectious diseases, and antidiabetic properties.

In the same manner, some evidences suggest that tea consumption may reduce the risk of cardiovascular disease and this health benefit is thought to be largely due to flavonoids. Some isolated flavonoids found in tea have also positive effects in inhibiting the development of atherosclerosis in animal models. ${ }^{5}$

In Brazil, a large number of native plants are used on a large scale as food or medicines and sometimes there are problems in identifying the plant used. ${ }^{6}$ A good example of this is the plant that is harvested in southern Brazil and sold as espinheira-santa. The species registered for alimentary/medicinal purposes in the Brazilian Pharmacopoeia is Maytenus ilicifolia (Schrad.) Planch., Celastraceae and the use of the leaves is recommended. ${ }^{7}$ It is widely used in Brazilian folk medicines in the form of aqueous infusions as anti-ulcers and against stomach diseases and also as beverages in daily life instead of green tea. ${ }^{8}$

Several articles in the literature describe possible anti-inflam-

*e-mail: flaviobeltra@gmail.com matory, hypotensive, vasorelaxant, antinociceptive and antioxidant effects of Maytenus ilicifolia as well as a protection against gastric ulcers. Normally these actions are attributed to the presence of phenolic metabolites and triterpenes. ${ }^{9-16}$

The ANVISA (National Agency of Sanitary Surveillance - Brazil) has approved, for the treatment of gastric disorders, the use and sale of phytomedicines from $M$. ilicifolia, which are standardized only by their tannin. ${ }^{7,17}$ For this reason, many Brazilian pharmaceutical industries and shops, produce and market phytopharmaceuticals containing this plant. ${ }^{18}$

It is well accepted that for evaluating the quality of crude herbal material and phytomedicines it is necessary to standardise the content of the active principles. However, when the active principles are not known, a compound, which is the most representative of the chemical composition of the extract, may be selected as the marker (chemical marker). 17,19,20

Nowadays, a great deal of effort is dedicated to characterising and quantifying metabolites of plants. In addition, it is important to develop new methods that can provide rapid information about factors such as authenticity and adulteration. ${ }^{21}$ Methods using chromatographic techniques may be employed in determining the metabolic profiles of herbal products. ${ }^{22}$ The advantages of liquid chromatography (LC) include its high reproducibility, its ease of automation and its ability to analyse a large number of constituents in botanicals and in herbal preparations, although most of the time the generated data are also too complex to be interpreted visually. ${ }^{23}$ In order to accomplish this task, multivariate analysis of the resulting data is a promising strategy. Based on the conception of phytoequivalence, the chromatographic fingerprints of herbal medicines can be utilised to address the problem of quality control of herbal medicines as reviewed by Liang et al. ${ }^{24}$ The use of chromatographic techniques, combined with chemometric approaches, 
has shown its value with herbal medicines such as Rhizoma chuanxiong and Ginkgo biloba. ${ }^{22}$ In the latest decade, this approach has become a tool for the interpretation and quality assessment of industrial and natural products. ${ }^{25}$ Exploratory data analysis consists mainly of principal component analysis (PCA), which provides a way to summarise the information contained in large sets of spectra. The initial variables (or measurements) are transformed into a much smaller set of variables or principal components (PC), ${ }^{26}$ and the explanation of what each PC represents in relation to the original measurements lies in the loadings.

Previously, we already reported the analysis of some samples of M. ilicifolia obtained in the commercial market, using pharmacopeical methods. ${ }^{27}$ In order to propose a new, rapid and efficient technique to confirm and evaluate the quality and authenticity of herbal medicines that use M. ilicifolia as the herbal product, the use of LC data together with multivariate analysis is reported in this work for the classification of commercial samples of espinheira-santa. Furthermore, a method for quantification of epicatechin (as a chemical marker) in commercial samples of espinheira-santa is described.

\section{EXPERIMENTAL}

\section{Plant material}

Maytenus ilicifolia leaves were obtained in Maringá, Brazil, in May 2006. The plant was identified and a voucher (Exsiccate HUM-10.602) was deposited in the Herbarium of the Maringá State University.

The commercial samples were obtained in commercial pharmacies.

\section{Chemicals}

Acetonitrile (ACN) and methanol $(\mathrm{MeOH})$ were HPLC-grade (J.T.Baker, Philipsburg, PA, USA). Acetic acid (AcOH) was analytical grade (Synth, Diadema, SP, Brazil). Water was purified with a Millipore Milli-Q system (Millipore, São Paulo, SP, Brazil) and it was used for all experiments. The silica used was phenylhexil (Luna ${ }^{\circledR}, 10 \mu \mathrm{m}$ particle size and 100 A pore size) and the column packed as described. Epicatechin (purity $>99.0 \%$ ) was purchased from Rhodia Pharma ${ }^{\circledR}$.

\section{Instrumentation and chromatographic columns}

For the quantification analysis a gradient Waters 2695 Alliance HPLC system (Milford, MA, USA) was employed and it was composed of a quaternary pump, an on- line degasser and an auto injector. A photo diode array detector (Waters 2998 - DAD) was used for the peak purity determination.

The column was packed by the ascending slurry method, using methanol for the preparation of the slurry $(50 \mathrm{~mL})$ and for the packing. These were carried out at a pressure of $7500 \mathrm{psi}$. The dimensions for the analytical columns were of $15 \times 0.46 \mathrm{~cm}$ I.D.

\section{The LC analysis}

\section{LC fingerprinting analysis}

The filtered extracts (standard and samples) were injected and then analysed using the phenylhexil column by gradient elution with methanol (B) in water (A) - (30 to $55 \%$ in $25 \mathrm{~min}, 55$ to $100 \%$ in $10 \mathrm{~min}$, an isocratic run at $100 \%$ of $\mathrm{B}$ was maintained for $5 \mathrm{~min}$ before doing the reverse gradient to $30 \%$ of $\mathrm{B}(10 \mathrm{~min}), \Delta \% \mathrm{~B}=1)$. The injected volume was $40 \mu \mathrm{L}$ and the flow rate was $1 \mathrm{~mL} / \mathrm{min}$. The detection was made by photo diodo array detector (DAD detector 200-400 nm).

\section{The quantitative analytical LC analysis}

The analytical separations were carried out using the phenylhexil column and the mobile phase consisted of a solution of ACN (B) in water with $\mathrm{AcOH} 0.1 \%$ (A) at the following gradient 5 to $60 \%$ in $25 \mathrm{~min}$. After this, the reverse gradient to $5 \%$ of B is executed in 5 min. The injected volume was $40 \mu \mathrm{L}$ and the flow-rate was $1 \mathrm{~mL} /$ $\min$. The chromatograms were recorded at $210 \mathrm{~nm}$. The samples and standard were prepared and filtered using the same conditions described below.

\section{Standard and samples}

Preparation of stock, standard and quality control solutions

A stock solution of epicatechin $(500 \mu \mathrm{g} / \mathrm{mL})$ was prepared in methanol. From this solution, 7 standard solutions of: 540, 378, 270, $162,108,54$ and $27 \mu \mathrm{g} / \mathrm{mL}$ were prepared by adding the appropriate amount, drying under air and then dissolving it using water: $\mathrm{MeOH}$ $(50: 50, \mathrm{v} / \mathrm{v})$ as solvent. Following the same procedure, the stock solution was also used to prepare the three quality control solutions: 403,320 and $116.3 \mu \mathrm{g} / \mathrm{mL}$.

\section{Preparation of standard and sample extracts}

A hydroalcoholic extract of pulverized air-dried leaves $(0.1 \mathrm{~g} /$ $\mathrm{mL}, 200 \mu \mathrm{m}$ particle size) of M. ilicifolia and samples (12) were prepared in water:ethanol $(30: 70, \mathrm{v} / \mathrm{v})$, at room temperature for 7 days, in darkness. The samples were previously filtered through a $0.5 \mu \mathrm{m}$ pore size filter (Millipore, Bedford, USA) prior to injection.

\section{Method validation}

\section{External standard curve}

Using the appropriate standard solution of epicatechin (540, 378, 270, 162, 108, 54 and $27 \mu \mathrm{g} / \mathrm{mL}$ ), the calibration standards were prepared in triplicate. The calibration curve was drawn by plotting the peak area against the concentration of the compound.

\section{Standard addition curve}

Aliquots $(100 \mu \mathrm{L})$ of the appropriate standard solutions of epicatechin were added to a constant amount $(200 \mu \mathrm{L})$ of Maytenus ilicifolia standard tincture. The samples were prepared in triplicate and filtered through a $0.5 \mu \mathrm{m}$ pore size filter prior to injection. Calibration curve was made by plotting the peak area against the concentration of the added compound.

\section{Recovery, intermediate precision and accuracy}

The relative recovery was examined using 3 quality control solutions prepared in water: $\mathrm{MeOH}(50: 50, \mathrm{v} / \mathrm{v})$ at 403, 320 and 116.3 $\mu \mathrm{g} / \mathrm{mL}$. The peak area ratios of three-filtered control solutions at each concentration were compared with the three standard solutions to derive a percent recovery.

The accuracy and inter and intra-day variability of the method were evaluated by replicate analysis at the same three concentrations that were used for the recovery experiment. Three samples of each concentration were prepared and analysed on two non-consecutive days. The accuracy of the method was evaluated by back calculation and tested by using blind unknowns at two different concentrations; they were prepared by different analysts.

\section{Selectivity}

A DAD UV-VIS detector was used to identify epicatechin and also to check peak purity at the analytical run of the standard tincture. The retention factor of the standard epicatechin was also used for identification at analytical run. 


\section{Limits of detection and quantification}

The limit of detection (LOD) was calculated by taking a signalto-noise ratio of three as criterion, while the acceptance criterion for the limit of quantification (LOQ) was the coefficient of variation (CV) and accuracy for three extracted samples up to $20 \%$ variability.

\section{Robustness}

Three sample solutions were prepared and analysed under the established conditions and by changing the wavelength parameter from 210 to $220 \mathrm{~nm} \cdot{ }^{28}$

\section{Data analysis}

Data acquisition, analysis and reporting were performed using Empower chromatography software (Milford, MA, USA). The resulting data matrix was imported into Microsoft Excel and multivariate analyses were performed with Pirouette software ${ }^{\circledR}$.

\section{RESULTS AND DISCUSSION}

To obtain initial information on the compounds present in the crude hydroalcoholic extract of $M$. ilicifolia, a liquid chromatographic-DAD (200-400 nm) analysis using an phenylhexil silica column with gradient elution of methanol (B) in water (A) -5 to $100 \%$ of B in $60 \mathrm{~min}$ - was evaluated. ${ }^{29}$

No compounds of high polarity and absorption were observed in the beginning of the run that could have interfered with the analysis, so the gradient elution conditions were optimised to 30 to $55 \%$ in $25 \mathrm{~min}, 55$ to $100 \%$ in $10 \mathrm{~min}$, an isocratic run at $100 \%$ of B was maintained for 5 min before doing the reverse gradient to $30 \%$ of $\mathrm{B}$ (10 $\min )(\Delta \% \mathrm{~B}=1)$ to obtain a fingerprinting chromatogram.

These conditions were applied to commercial samples and a visual analysis of the chromatograms did not show clear differences, although a variation in the intensities of the same signals could be observed. The fingerprinting chromatogram is complex thus a possible approach is to observe the metabolite profile as a whole using multivariate methods, for example, by application of PCA. For this, to evaluate the similarities and the differences between the samples and the standard sample, a chemometric evaluation was applied

Prior to PCA analysis, the chromatographic data were auto-scaled (pre-processing) and normalised.

The number of replicates employed was 3 . The results demonstrated that the PCA scores plot showed a similar distribution for the samples. The replicate of $M$. ilicifolia standard joined to all samples, but was different from sample 4 that visually did not show a different profile (Figure 1).

This result is in accordance with previously reported work of our group in which we demonstrated by histological analysis that sample 4 was not a M. ilicifolia sample. ${ }^{27}$

Although the PCA scores could be used to classify the samples, it is important for quality control analysis to quantify a specific marker to prove the quality of the compounds present in the material. For this purpose, a quantitative method was developed employing epicatechin as chemical marker of the M. ilicifolia species, as recommended by the Brazilian Pharmacopoeia. ${ }^{7,18,30}$

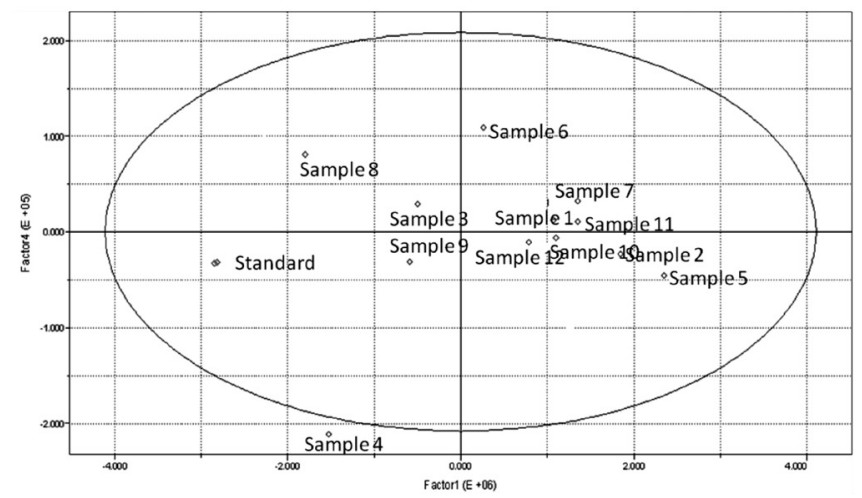

Figure 1. PCA scores plot of LC chromatogram data

To achieve this goal, a LC-DAD system was applied making the proposed method adequate to be used in the quality control of herbal medicines made from $M$. ilicifolia.

The response of the UV detector at $210 \mathrm{~nm}$ was linear from 540$27 \mu \mathrm{g} / \mathrm{mL}$ for epicatechin and the chromatograms recorded showed considerable improvement in the signal-to-noise ratio. The regression equation found was $y=700.4 \mathrm{x}-8073$, with a correlation coefficient of $r=0.997$ with a coefficient of variation $(\mathrm{CV} \%)$ of $<5 \%$ for the triplicate analysis. ${ }^{28}$

Under the chromatographic conditions used the peak purity was examined between 200 and $300 \mathrm{~nm}$ using a photo diode array detector for the selectivity evaluation, confirming the absence of impurities.

The recoveries of epicatechin were determined by analysing the quality control samples at three different concentrations. The peak-area ratios of three extracted samples at each concentration were compared with those of three injections of standard solutions to derive a percent recovery. The recoveries are presented in Table 1.

Table 1. Extraction recovery of epicatechin

\begin{tabular}{lccc}
\hline & $\begin{array}{c}\text { Concentration }(\mu \mathrm{g} / \\
\mathrm{mL})\end{array}$ & $\begin{array}{c}\text { CV \% } \\
(\mathrm{n}=3)\end{array}$ & $\begin{array}{c}\text { Recovery } \% \\
(\mathrm{n}=3)\end{array}$ \\
\hline Epicatechin & 116.3 & $2.52 \%$ & $93.22 \%$ \\
& 320 & $1.54 \%$ & $98.17 \%$ \\
& 403 & $1.58 \%$ & $96.32 \%$ \\
\hline
\end{tabular}

The intra and inter-day precision and accuracy of the method were determined by analysing three replicates of the three quality controls on two non-consecutive days. Precision is expressed as CV\% and the accuracy was evaluated by back-calculation and expressed as the percent deviation between amount found and amount added to the three concentrations examined. The results are shown in Table 2 and led to satisfactory intra- and inter-assay precision, with a CV\% of $<5 \%$ and the accuracy varied from 94.8 to $100.7 \%$.

The concentration of $13.5 \mu \mathrm{g} / \mathrm{mL}$ was the limit of quantification with an accuracy of $120.45 \%$ while the limit of detection was 8.1 $\mu \mathrm{g} / \mathrm{mL}$.

Two blind samples containing concentrations unknown to the analyst produced accuracy in the range of $95.8-100.8 \%$ at the concentration levels of 240 and $385 \mu \mathrm{g} / \mathrm{mL}$ with $\mathrm{CV} \%$ at the range of

Table 2. Accuracy and intra and inter-day for the assay of epicatechin

\begin{tabular}{|c|c|c|c|c|c|c|}
\hline & \multirow{2}{*}{$\begin{array}{l}\text { Concentration } \\
(\mu \mathrm{g} / \mathrm{mL})\end{array}$} & \multicolumn{2}{|c|}{$1^{\text {st }}$ day $(n=3)$} & \multicolumn{2}{|c|}{$2^{\text {nd }}$ day $(n=3)$} & \multirow{2}{*}{$\begin{array}{c}\text { Pooled }(\mathrm{n}=3) \\
\text { CV }(\%)\end{array}$} \\
\hline & & $\mathrm{CV}(\%)$ & Accuracy $(\%)$ & $\mathrm{CV}(\%)$ & Accuracy $(\%)$ & \\
\hline \multirow[t]{3}{*}{ Epicatechin } & 116.3 & 0.96 & 96.4 & 1.39 & 94.8 & 1.17 \\
\hline & 320 & 0.39 & 100.7 & 0.62 & 97.0 & 0.50 \\
\hline & 403 & 1.06 & 95.3 & 1.94 & 97.3 & 1.50 \\
\hline
\end{tabular}


0.17 and 1.78 for the duplicate analysis. Typical chromatogram of epicatechin analysis obtained during the validation study is shown in Figure 2.

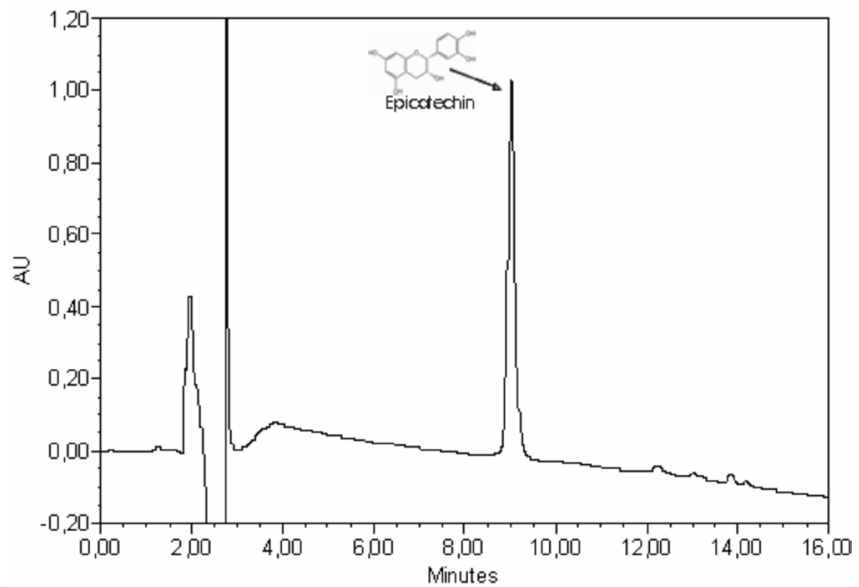

Figure 2. Typical chromatogram of the analysis of epicatechin obtained during the validation method using the phenyl-hexil column and the mobile phase consisted of a solution of $\mathrm{ACN}(\mathrm{B})$ and $\mathrm{H}_{2} \mathrm{O}$ with $\mathrm{AcOH} 0.1 \%$ (A) at the following gradient 5 to $60 \%$ in $25 \mathrm{~min}$, after this, the reverse gradient to $5 \%$ of $B$ is executed in $5 \mathrm{~min}$. The injected volume was $40 \mu \mathrm{L}$ and the flow-rate was $1 \mathrm{~mL} / \mathrm{min}$. The chromatograms were recorded at $210 \mathrm{~nm}$

A standard addition calibration curve was also carried out. This was done to evaluate matrix interferences. This calibration curve was obtained by the analysis of five added concentrations of epicatechin to the standard samples extract in the $54-378 \mu \mathrm{g} / \mathrm{mL}$ range. The following regression equation and correlation coefficient were obtained: $\mathrm{y}=1414 \mathrm{x}+20823, \mathrm{r}=0.991$.

Good correlation was observed for quantification of a standard sample using the external calibration curve and the standard addition curve. Using the standard addition curve, the value obtained for the absolute recovery of the method was $98.0 \%$.

The validated methods were suitable for the quantitative analysis of epicatechin in eleven commercial samples of M. ilicifolia sold as espinheira-santa in the Brazilian market. Identification of epicatechin in these samples was confirmed by the retention time obtained from the authentic samples (Figure 3 and Table 3).

As determined by PCA analysis, the LC-DAD chromatogram of
Table 3. Results obtained for the quantification of epicatechin in commercial samples sold as espinheira-santa in the Brazilian market

\begin{tabular}{lc}
\hline Samples & Epicatechin $(\% *)$ \\
\hline Espinheira santa (Maringá) & 90.21 \\
Espinheira santa (Londrina) & 87.70 \\
Espinheira santa (Marialva) & 85.82 \\
Espinheira santa (Curitiba) & 82.62 \\
Espinheira santa (Maringá) & 67.81 \\
Espinheira santa (Ortigueira) & 62.79 \\
Espinheira santa (Curitiba) & 52.55 \\
Espinheira santa (Toledo) & 41.58 \\
Espinheira santa (Colombo) & 41.20 \\
Espinheira santa (Mandaguari) & 40.51 \\
Espinheira santa (Uraí) & 39.67 \\
Espinheira santa (Mauá da Serra) & not found
\end{tabular}

* Maytenus ilicifolia standard sample (epicatechin concentration: $277.5 \mu \mathrm{g} / \mathrm{mL}$ - corresponding to $100 \%$ ).

sample 4, that was purchased as espinheira-santa in a commercial pharmacy in the city of Mauá da Serra (Paraná, Brazil), did not show the epicatechin peak, indicating that this sample has a low quality or is not a $M$. ilicifolia species.

\section{CONCLUSION}

The qualitative LC method developed and employed to evaluate the $M$. ilicifolia samples, presented here, is simple and allows classifying the similarities and the differences of $M$. ilicifolia. Also, a quantitative and selective method was developed and used to identify and quantify epicatechin in raw materials of M. ilicifolia. Thus, these methods can be used for the quality control of raw material and herbal medicines made with this plant by pharmaceutical laboratories.

\section{SUPPLEMENTARY MATERIAL}

The chromatograms of commercial samples (Figure 1S to $11 \mathrm{~S}$ ) are presented on http://quimicanova.sbq.org.br, in PDF format with free access.
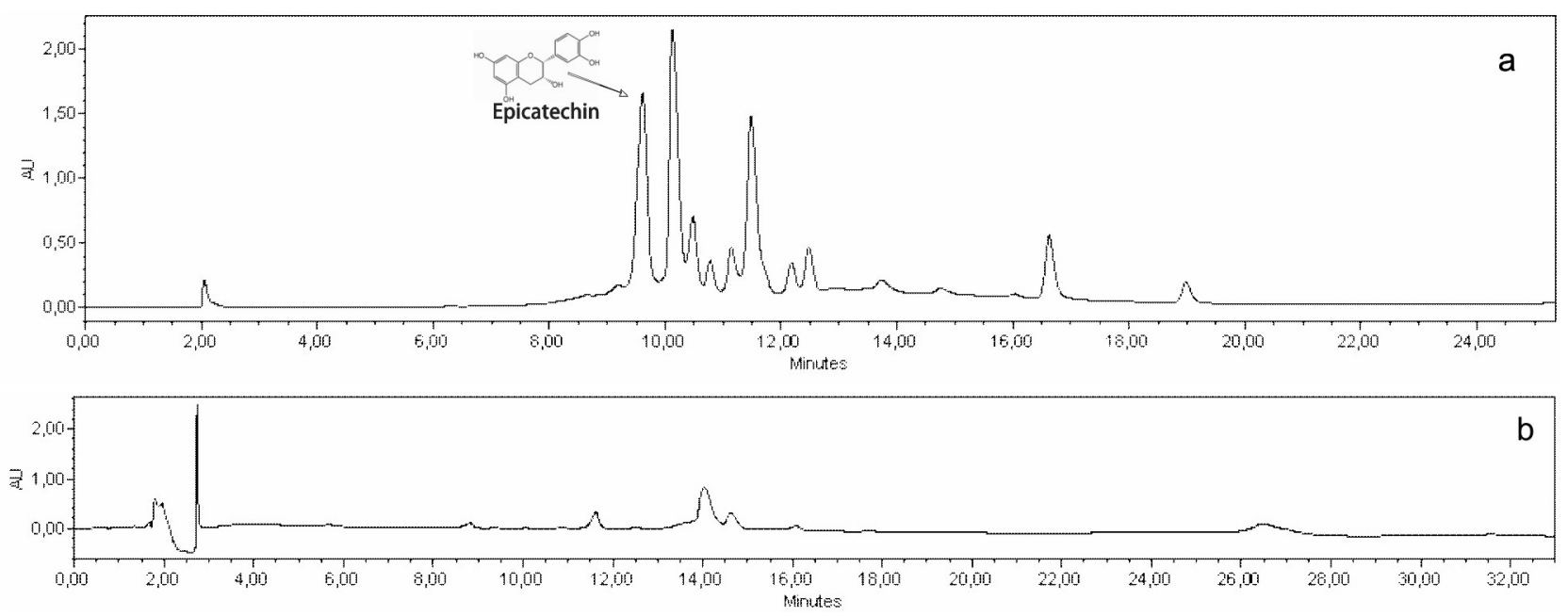

Figure 3. Typical chromatogram of: (a) standard sample of Maytenus ilicifolia; (b) a commercial sample bought as espinheira-santa in Mauá da Serra city (did not show the epicatechin peak) 


\section{ACKNOWLEDGEMENTS}

To Fundação Araucária for financial support.

\section{REFERENCES}

1. Gao, Y. T.; McLaughlin, J. K.; Blot, W. J.; Ji B. T.; Dai, Q.; Fraumeni, J. F.; J. Natl. Cancer Inst.1994, 86, 855.

2. Afaq, F.; Adhami, V. M.; Ahmad, N.; Mukhtar, H.; Antioxid. Redox Signaling 2004, 6, 571.

3. Yang, G.; Shu, X. O.; Li, H.; Chow, W. H.; Ji, B. T.; Zhang, X.; Gao, Y. T.; Zheng, W.; Cancer Epidemiol. Biomarkers Prev. 2007, 16, 1219.

4. Chen, H.; Qu, Z.; Fu, L. ; Dong, P.; Zhang, X.; J. Food Sci. 2009, 74, 469.

5. Hodgson, J. M.; Crofta, K. D.; Mol. Aspects Med. 2010, 31, 495.

6. Beltrame, F. L.; Rodrigues Filho, E.; Barros, F. A. P.; Cortez, D. A. G.; Cass, Q. B.; J. Chromatogr., A 2005, 119, 257.

7. Farmacopéia Brasileira, 4a ed., Comissão Permanente de Revisão da Farmacopéia Brasileira, Atheneu: São Paulo, 2002.

8. Leite, J. P. V.; Rastrelli, L.; Romussi G.; Oliveira, A. B.; Vilegas, J. H. Y.; Vilegas, W.; Pizza, C.; J. Agric. Food Chem. 2001, 49, 3796.

9. Ogava, S. E. M.; Pinto, M. T. C.; Kikuchi, T.; Menegueti, V. A. F.; Martins, D. B. C.; Coelho, S. A. D.; Marques, M. J. N. J.; Virmond, J. C. S.; Monteschio, P.; D’Aquino, M.; Marques, L. C.; Rev. Bras. Farmacogn. 2003, 13, 58.

10. Nunes, G. P. I.; da Silva, M. F. I.; Resende, U. M. I.; Siqueira, J. M.; Rev. Bras. Farmacogn. 2003, 13, 83.

11. Souza, C. D.; Felfili, J. M.; Acta Bot. Bras. 2006, 20, 135.

12. Rattmann, Y. D.; Cipriani, T. R.; Sassaki, G. L.; Iacomini, M.; Rieck, L.; Marques, M. C. A.; Silva-Santos, J. E.; J. Ethnopharmacol. 2006, 104, 328.

13. Vellosa, J. C. R.; Khalil, N. M.; Formenton, V. A. F.; Ximenes, V. F.; Fonseca, L. M.; Furlan, M.; Brunetti, I. L.; Oliveira, O. M. M. F.; Fitoterapia 2006, 77, 243.
14. Crestani, S.; Rattmann, Y. D.; Cipriani, T. R.; Souza, L. M.; Iacomini, M.; Kassuya, C. A. L.; Marques, M. C. A.; Silva-Santos, J. E.; Vasc. Pharmacol. 2009, 51, 57.

15. Silva, M. D.; Dreveck, S.; Zeni, A. L. B.; Health Environ. J. 2009, 10, 54.

16. Pessuto, M. B.; Costa, I. C.; Souza, A. B.; Nicoli, F. M.; Quim. Nova 2009, 32, 412

17. ANVISA; Resolução da Diretoria Colegiada 14, de 05/4/2010 - dispõe sobre o registro de medicamentos fitoterápicos, Ministério da Saúde: Brasília, 2010; http://portal2.saude.gov.br, acessada em Agosto 2011.

18. Lopes, G. C.; Blainski, A.; Santos, P. V. P.; Diciaula, M. C.; Mello, J. C. P.; Rev. Bras. Farmacogn. 2010, 20, 781.

19. Calixto, J. B.; Braz. J. Med. Biol. Res. 2000, 33, 179.

20. Ong, E. S.; J. Chromatogr., B: Anal. Technol. Biomed. Life Sci. 2004, $812,23$.

21. Daolio, C.; Beltrame, F. L.; Cass, Q. B.; Ferreira, M.; Ferreira, A.; Phytochem. Anal. 2008, 19,18.

22. Gong, F.; Liang, Y. Z.; Xie, P. S.; Chao, F. T.; J. Chromatogr., A 2003, $100,25$.

23. Belton, P. S.; Colquhoun, I. J.; Kemsley, E. K.; Delgadillo, I.; Roma, P.; Dennis, M. J.; Sharman, M.; Holmes, E.; Nicholson. J.; Spraul, M.; Food Chem. 1998, 61, 207.

24. Liang, Y. Z.; Xie, P. S.; Chan, K.; J. Chromatogr., B: Anal. Technol. Biomed. Life Sci. 2004, 812, 53.

25. Kim, H. K.; Choi, Y. H.; Erkelens, C.; Lefeber, A. W. M.; Verpoorte, R.; Chem. Pharm. Bull. 2005, 53, 105.

26. Defernez, M.; Colquhoun, I. J.; Phytochemistry 2003, 62, 1009.

27. Chimin, A.; Lima, E. L.; Beltrame, F. L.; Pereira, A. V.; Esmerino L. A.; Lat. Am. J. Pharm. 2008, 27, 591.

28. ANVISA; Resolução da Diretoria Colegiada 899, de 29/5/2003, Guia Sanitário, Ministério da Saúde: Brasília, 2003; http://portal.anvisa.gov. br, acessada em Agosto 2011.

29. Snyder, L. R.; Dolan, J. W.; J. Chromatogr., A 1996, 721, 3.

30. Santana, I. G.; Severo, I. L.; Almeida, L. C.; Pereira, P. I. R. M.; Silva, E. M.; Bara, M. T. F.; Revista Eletrônica de Farmácia 2007, 4, 54. 